\title{
Cataract in leprosy patients: cataract surgical coverage, barriers to acceptance of surgery, and outcome of surgery in a population based survey in Korea
}

\author{
Paul Courtright, Susan Lewallen, Narong Tungpakorn, Byeong-Hee Cho, \\ Young-Kyu Lim, Hyun-Ji Lee, Sung-Hwa Kim
}

\section{British Columbia Centre for Epidemiologic and International Ophthalmology, University of British Columbia, Vancouver, BC, Canada P Courtright \\ $S$ Lewallen}

Department of Ophthalmology, Chiang Mai University, Thailand

N Tungpakorn

Department of Sociology, Keimyung University, Taegu, South Korea

B-H Cho

Y-K Lim

H-J Lee

School of Public Health, Seoul National University, Seoul, South Korea B-H Cho

Catholic Skin Clinic and Hospital, Taegu, South Korea

S-H Kim

Correspondence to: Paul Courtright, British Columbia Centre for Epidemiologic and International

Ophthalmology, University of British Columbia, St Paul's Hospital, 1081 Burrard Street, Vancouver, BC, V6Z 1Y6, Canada pcourtright@

providencehealth.bc.ca

Accepted for publication 20 December 2000

\begin{abstract}
Backgroundlaims-Cataract is the leading cause of blindness in leprosy patients. There is no population based information on the cataract surgical coverage, barriers to use of surgical services, and outcome of surgery in these patients. We sought to determine these measures of cataract programme effectiveness in a cured leprosy population in South Korea.

Methods-The population consisted of residents of six leprosy resettlement villages in central South Korea. All residents were invited to participate in a study of eye disease and interviewed regarding use of surgical services and reasons for not using these services.

Results-The cataract surgical coverage in this population was $55.4 \%$ when $<6 / 18$ was used as the cut off and increased to $78.3 \%$ when the cut off was $<6 / 60$. Barriers reported by patients included being told by the doctor that the cataract was not mature and a perception by the patient that there was no need for surgery. Among patients who had aphakic surgery, $71 \%$ were still blind in the operative eye while among patients who had pseudophakic surgery, $14 \%$ were still blind (presenting vision). Blindness in pseudophakic patients could be reduced to $3 \%$ with spectacle correction.

Conclusion-Cataract prevalence in leprosy patients will increase as life expectancy continues to increase. Leprosy control programmes will need to develop activities aimed at reducing the burden of cataract. Recommendations include establishing collaborative agreements with ophthalmological services to provide high quality IOL surgery to these patients, training of health staff to identify and refer patients in need of surgery, monitoring the uptake of cataract surgery among patients needing services, and monitoring the outcome of surgery to improve refractive outcome.

(Br F Ophthalmol 2001;85:643-647)
\end{abstract}

Cataract is the leading cause of blindness in leprosy patients. ${ }^{1}$ In addition to being at risk for blindness due to typical age related cataract, leprosy patients are also at risk of complicated cataract due to chronic or acute uveitis. $^{23}$ While the magnitude of this excess risk has not been adequately defined, it is estimated that uveitis increases the risk of cataract threefold. ${ }^{4}$ There is evidence from India and the Philippines that multibacillary patients on multidrug therapy (MDT) continue to develop chronic uveitis during and after successful antileprosy treatment (Courtright, unpublished data).

Globally, there are approximately 1.5 million people on MDT for leprosy. ${ }^{5}$ In addition to leprosy cases under treatment there are an estimated 8-12 million cured patients and growing numbers who have completed MDT and have been removed from the official registers of those with the disease.

There are several reasons why it is important to understand cataract in leprosy patients. Firstly, cataract in both cured and uncured leprosy patients can be expected to increase in the coming years, primarily due to increased life expectancy. All ageing leprosy patients are at risk for age related cataract and many of the multibacillary patients are at risk for complicated cataract. Secondly, leprosy patients, who often have anaesthetic digits, are doubly disadvantaged when they lose their sight. Thirdly, leprosy patients in most parts of the world are extremely poor as well as being stigmatised, and thus are the least likely among those with cataract to receive eye services.

Among ophthalmologists who work with leprosy patients, there has been discussion about the feasibility and safety of using intraocular lenses (IOLs) for cataract. ${ }^{6}$ Even a decade ago there was concern about the safety of removing cataract at all in this population. The concern is due to the fact that a large percentage of cataract in multibacillary leprosy patients is the complicated type, with dense synechiae and extreme miosis, and surgery can be difficult. Furthermore, there is probably an 
increased potential for anterior chamber inflammation in this population, even among cured patients. The risk of poor outcome is further increased by the fact that many patients may receive surgery in less than ideal circumstances. Previous case series reports of the outcome of cataract surgery have shown variable success rates..$^{7-14}$

The issue of the barriers that keep general cataract patients from receiving surgery has received increasing attention in the past few years. ${ }^{15-18}$ It has become apparent that many cataract patients do not take advantage of services because of cost, distance to service, fear of surgery, fear of poor outcome, sex discrimination, and other factors. The barriers to the use of cataract surgery among a population of leprosy patients may differ from those in nonleprosy populations and have not been investigated before. This information would help leprosy control and blindness prevention programmes create interventions aimed at increasing access to and uptake of cataract surgery.

We sought to determine the cataract surgical coverage rate (percentage of those needing surgery who have received it), the barriers which prevented patients from receiving surgery, and the outcome of surgery in a population of cured leprosy patients with access to modern high quality ophthalmological services.

\section{Methods}

STUDY SITE

The population we studied has been described before. ${ }^{19}{ }^{20}$ Briefly, they are the inhabitants of six of the eight leprosy villages under the care of the Catholic Skin Clinic and Hospital in Taegu, South Korea. For the purpose of this study we have defined distant villages as those three villages $10 \mathrm{~km}$ or more from the hospital. The incidence of leprosy now in South Korea is very low $(0.1 / 100000)$ and this is an ageing population. It is estimated that there are 18800 current and cured leprosy patients in Korea. Since 1989 an ophthalmologist and a well equipped eye clinic and surgical theatre have been available at the Catholic Skin Clinic and Hospital. The only other routine ophthalmological service provided to leprosy patients is from the Yonsei University Department of Ophthalmology for leprosy patients at the Korean Leprosy Institute near Seoul.

\section{STUDY POPULATION}

The 1988 ocular survey of residents of the six villages included presenting visual acuity, external examination for trichiasis and lagophthalmos, and slit lamp and ophthalmoscopic examination of the anterior segment and posterior pole. ${ }^{20}$ Patients with significant cataract (vision $<6 / 18$ ) were referred to the Catholic Skin Clinic and Hospital eye clinic where surgery is available free of charge.

In 1999 a follow up survey was carried out; the same clinical variables recorded in 1988 were recorded in 1999; these results are reported elsewhere. ${ }^{19}$ Several weeks after the clinical examinations, three questionnaires, (1) visual function, (2) quality of life, and (3) use of eye care services were administered to all
Table 1 Cataract surgical coverage

\begin{tabular}{lll}
\hline \multirow{3}{*}{ Visual acuity } & \\
\cline { 2 - 3 } & $<6 / 60$ & $<6 / 18$ \\
\hline People & $36 / 46(78.3 \%)$ & $36 / 65(55.4 \%)$ \\
Males & $19 / 23(82.6 \%)$ & $19 / 34(55.9 \%)$ \\
Females & $17 / 23(73.9 \%)$ & $17 / 31(54.8 \%)$ \\
\hline
\end{tabular}

patients who had evidence of cataract surgery or had cataract with vision less than $6 / 18$ in the better eye. The questionnaires were administered by two trained graduate students from the Department of Sociology, Keimyung University. Findings from the visual function and quality of life questionnaires are not reported here. The use of eye care questionnaire covered barriers to use of services and satisfaction with services received. All forms were pretested in one of the villages before the start of the study.

For the purpose of this study, several definitions were set. Patients who were pseudophakic in one eye and aphakic in the other eye were classified as "pseudophakic". We defined cataract surgical coverage as the number of people who have had cataract surgery in one or both eyes by the total number of people with cataract. ${ }^{21}$ Although three levels of cataract are generally defined (cataract causing vision of less than $6 / 18$, less than $6 / 60$, and less than $3 / 60$ ) we collapsed the last two as there were no people between $6 / 60$ and $3 / 60$. In the case where the fellow eye in a unilaterally operated-on person was not of the specified level of vision loss, they were excluded from the cataract surgical coverage calculation. In Korea cataract surgery is recommended in patients with a vision of $6 / 24$ or worse and we have chosen $<6 / 18$ as our cut off for assessing barriers to use of surgical services.

Odds ratios and $95 \%$ confidence intervals were used to compare potential factors associated with surgery versus no surgery and to compare the outcome of aphakic versus pseudophakic surgery.

\section{Results}

CATARACT SURGICAL COVERAGE AND BARRIERS TO ACCEPTANCE OF SURGERY

In 1999 clinical examinations were conducted on 270 leprosy patients. Of these, 36 patients had undergone cataract surgery while 29 still had a visually significant $(<6 / 18$ in better eye) cataract, giving a cataract surgery coverage of $55.4 \%$. There were no patients in whom presenting vision was $3 / 60-5 / 60$ so the cut off of $<6 / 60$ is the same as for $<3 / 60$. Among this group the cataract surgical coverage was $78.3 \%$ (Table 1). Using the $<6 / 18$ cut off, we have assessed uptake of surgery according to demographic factors of the population. Uptake was not associated with age, sex, leprosy type, duration or age at onset of leprosy (Table 2). There was a slight association between uptake and distance from the hospital; the two most distant villages, which were also the poorest, had the lowest surgical coverage $(42.9 \%)$. This was not associated with the type of surgery received.

Among 65 eligible for interview, 48 were interviewed; the 17 patients who were not 
Table 2 Uptake of cataract surgery among Korean leprosy patients (among visually impaired <6/18)

\begin{tabular}{|c|c|c|c|}
\hline & $\begin{array}{l}\text { Had surgery (\%) } \\
(n=36)\end{array}$ & $\begin{array}{l}\text { No surgery (\%) } \\
(n=29)\end{array}$ & Odds ratio $(95 \%$ CI) \\
\hline \multicolumn{4}{|l|}{ Age } \\
\hline$<70$ & $22(62.9)$ & $13(37.1)$ & \multirow[t]{2}{*}{$1.93(0.64-5.90)$} \\
\hline $70+$ & $14(46.7)$ & $16(53.3)$ & \\
\hline \multicolumn{4}{|l|}{ Village $^{\star}$} \\
\hline Nearby villages & $23(63.9)$ & $13(36.1)$ & \multirow{2}{*}{$1.63(0.51-5.26)$} \\
\hline Distant villages & $13(52.0)$ & $12(48.0)$ & \\
\hline \multicolumn{4}{|l|}{ Village $^{\star}$} \\
\hline Rich villages & $13(65.0)$ & $7(35.0)$ & \multirow[t]{2}{*}{$1.61(0.48-5.59)$} \\
\hline Poor villages & $23(53.5)$ & $20(46.5)$ & \\
\hline \multicolumn{4}{|l|}{ Leprosy type } \\
\hline Multibacillary & $33(55.9)$ & $26(44.1)$ & \multirow{2}{*}{$1.27(0.18-8.80)$} \\
\hline Paucibacillary & $3(50.0)$ & $3(50.0)$ & \\
\hline \multicolumn{4}{|l|}{ Duration of leprosy } \\
\hline$<40$ years & $26(60.5)$ & $17(39.5)$ & \multirow[t]{2}{*}{$1.68(0.52-5.50)$} \\
\hline $40+$ years & $10(47.6)$ & $11(52.4)$ & \\
\hline Mean age & $69.5(6.4)$ & $70.5(8.5)$ & NS \\
\hline Mean age at onset & $20.8(5.4)$ & $21.6(6.5)$ & NS \\
\hline Duration of leprosy & $48.8(5.4)$ & $48.4(7.6)$ & NS \\
\hline
\end{tabular}

${ }^{\star}$ One village not included as it was not under the responsibility of the Catholic Skin Clinic and Hospital. Neither of the two cataract patients in this village had had surgery.

Table 3 Visual outcome of cataract surgery

\begin{tabular}{|c|c|c|c|}
\hline & $\begin{array}{l}\text { Aphakic patients } \\
(n=11)\end{array}$ & $\begin{array}{l}\text { Pseudophakic patients } \\
(n=25)\end{array}$ & Odds ratio $(95 \%$ CI $)$ \\
\hline \multicolumn{4}{|c|}{ Outcome, better eye (presenting) } \\
\hline$<6 / 60$ & $6(54.5)$ & $1(4.0)$ & \multirow[t]{3}{*}{$14.4(1.76-150.6)$} \\
\hline $6 / 24-6 / 60$ & $1(9.1)$ & $12(48.0)$ & \\
\hline \multirow[t]{2}{*}{$>6 / 24$} & $4(36.4)$ & $12(48.0)$ & \\
\hline & $\begin{array}{l}\text { Aphakic eyes } \\
(n=17)\end{array}$ & \multicolumn{2}{|l|}{$\begin{array}{l}\text { Pseudophakic eyes } \\
(n=36)\end{array}$} \\
\hline \multicolumn{4}{|c|}{ Visual acuity (presenting) } \\
\hline$<6 / 60$ & $12(70.6)$ & $5(13.9)$ & \multirow[t]{3}{*}{$14.9(3.1-81.3)^{\star}$} \\
\hline $6 / 24-6 / 60$ & $3(17.6)$ & $8(22.2)$ & \\
\hline$>6 / 24$ & $2(11.8)$ & $23(68.9)$ & \\
\hline \multicolumn{4}{|c|}{ Visual acuity (best corrected) } \\
\hline$<6 / 60$ & $11(64.7)$ & $1(2.8)$ & \multirow{3}{*}{$64.2(6.2-1606.5)^{\star}$} \\
\hline $6 / 24-6 / 60$ & $4(23.5)$ & $5(13.9)$ & \\
\hline$>6 / 24$ & $2(11.8)$ & $30(83.3)$ & \\
\hline
\end{tabular}

${ }^{\star} \mathrm{p}<0.001$.

present in the village at the time of interviews or who refused interviews were not different from interviewed patients in terms of age, sex, vision status, or surgery received (data not shown).

The reasons, sometimes multiple, given by patients with vision reducing cataract for not accepting cataract surgery were cataract not mature $(n=28)$, surgery was not needed $(n=9)$, other medical complications $(n=3)$, and fear of a poor outcome $(n=2)$.

OUTCOME OF CATARACT SURGERY

Among the 36 patients who had cataract surgery 25 were pseudophakic and 11 were aphakic. Overall, seven patients (19.4\%) were still blind (presenting vision $<6 / 60$ ) and 13 $(36.1 \%)$ were visually impaired (presenting vision 6/24-6/60). Among pseudophakic surgical cases, only one patient was still blind (Table 3). Visual outcome by eye also shows good outcomes for pseudophakic eyes; only $13.9 \%$ were still blind after surgery and this could be reduced to $2.8 \%$ with additional correction (Table 3). Pseudophakic eyes had significantly better visual acuity than aphakic eyes.

The clinical characteristics of surgical cases are shown in Table 4. Diminished corneal sensation was noted more commonly in aphakic eyes compared with pseudophakic eyes. This difference could not be attributed to disease type, duration of leprosy, or age. The only visually significant complications in the pseudophakic eyes were two eyes with opacification of the posterior capsule. In the 36 eyes in which pseudophakic surgery was done $12(33.3 \%)$ had evidence of posterior synechiae at the time of the 1988 examination; there was no difference in visual outcome of these patients compared with the patients without evidence of posterior synechiae. As only three patients had had aphakic cataract surgery in the past 11 years it was not possible in this group to compare outcome by the presence of posterior synechiae. Among the 11 aphakic eyes with a poor outcome, four had retinal co-morbidities, one had corneal opacity due to lagophthalmos, and six had surgery related complications.

\section{Discussion}

Cataract is the leading cause of blindness in leprosy patients and the number of cataract blind will grow as this population ages. In our Korean population cataract accounts for $87 \%$ of incident blindness. ${ }^{19}$ Once cataract patients are identified, cataract surgical services must be offered. However, simply making these

Table 4 Clinical characteristics of cataract surgery cases (by eye)

\begin{tabular}{|c|c|c|c|c|}
\hline & $\begin{array}{l}\text { Aphakic eyes } \\
(n=17)\end{array}$ & $\begin{array}{l}\text { Pseudophakic eyes } \\
(n=36)\end{array}$ & $\begin{array}{l}\text { No surgery eyes } \\
(n=108)\end{array}$ & $\begin{array}{l}\text { Odds ratiof } \\
(95 \% C I)\end{array}$ \\
\hline \multicolumn{5}{|l|}{ Lagophthalmos } \\
\hline \multicolumn{5}{|l|}{ Gentle closure } \\
\hline Normal & $12(70.6)$ & $30(83.3)$ & $85(78.7)$ & \\
\hline Abnormal & $5(29.4)$ & $6(16.7)$ & $23(21.3)$ & $0.48(0.10-2.28)$ \\
\hline \multicolumn{5}{|l|}{ Forced closure } \\
\hline Normal & $13(76.5)$ & $32(88.8)$ & $91(84.3)$ & \\
\hline Abnormal & $4(23.5)$ & $4(11.1)$ & $17(15.7)$ & $0.41(0.07-2.34)$ \\
\hline \multicolumn{5}{|l|}{ Corneal changes } \\
\hline \multicolumn{5}{|l|}{ Keratitis } \\
\hline Absent & $12(70.6)$ & $28(77.8)$ & $87(80.6)$ & \\
\hline Present & $5(29.4)$ & $8(22.2)$ & $21(19.4)$ & $0.69(0.16-3.06)$ \\
\hline \multicolumn{5}{|c|}{ Corneal sensation } \\
\hline Normal & $5(29.4)$ & $24(66.7)$ & $87(80.6)$ & \\
\hline Diminished & $12(70.6)$ & $12(33.3)$ & $21(19.4)$ & $0.21(0.05-.85) \ddagger$ \\
\hline \multicolumn{5}{|c|}{ Uveal changes (in 1988)* } \\
\hline \multicolumn{5}{|c|}{ Synechiae } \\
\hline Absent & $1(33.3)$ & $25(69.4)$ & $79(73.8)$ & \\
\hline Present & $2(66.6)$ & $11(30.6)$ & $18(26.2)$ & \\
\hline
\end{tabular}

* Synechiae could not be recorded in 14 patients with aphakic surgery as their surgery was before the 1988 examination time. †The odds ratio has been calculated to compare aphakic eyes with pseudophakic eyes. $\neq \mathrm{p}<0.001$. 
services available will not be enough, as shown by the high percentage of patients who have not accepted surgery. The uptake of cataract surgery among this population is fairly low, considering that surgery is free of charge, transportation systems are good, there is good contact between the hospital and the villages, and the clinical outcome of pseudophakic surgery is excellent. While we have no statistics on the uptake of surgery by the general rural population of Korea for comparison, most rural Koreans do not have access to free surgery. As has been found in many other nonleprosy rural populations, distance to the surgical facility is one barrier preventing patients from receiving surgery. ${ }^{16}{ }^{17}$ Either the services must be taken to the patients, or patients must be provided with transport to the services. Whichever method is used it is imperative that the quality of the surgical services is high. It appears from our findings that a major barrier to surgery is related to the service provider. Patients with visual impairment or blindness are under the impression that their cataracts are not "ready" for surgery. In non-leprosy patients in India it has been demonstrated that if large numbers of patients reporting for treatment are being told to wait then there is either inadequate capacity for surgery or the visual acuity cut off for surgery is too low. ${ }^{22}$

Our findings in this population indicate that implantation of intraocular lens results in good outcomes in leprosy patients. There are only a few other reports of outcome of intraocular lens implementation in leprosy patients. ${ }^{78} \mathrm{As}$ in our study, microscopes and viscoelastics were used in these reports and the findings should not be generalised to situations where surgeons are not well trained and modern equipment is not available. Surgery in eyes with complicated cataract is more difficult and poses a higher risk of serious problems than uncomplicated; however, our findings do not suggest that patients with posterior synechiae should be denied IOL surgery. In our population four of the five IOL patients who were still blind postoperation could be improved and made no longer blind by refraction. This suggests that vigorous follow up of surgical cases should be undertaken to provide spectacles.

There are a number of published reports describing cataract surgery without intraocular lenses in leprosy patients and the majority of patients described do have greatly improved visual acuity following surgery ${ }^{10-12}$; however, these studies are not recent. Furthermore, the indications for cataract surgery when intraocular lenses are not used are different from the indications when pseudophakia is an option. We defined significant cataract as one that decreased vision to less than $6 / 18$. Most of the aphakic patients in our population were operated over 10 years ago, when indications for cataract surgery were different and most cataracts were not removed until vision was $<3 / 60$. While $55 \%$ of our aphakic patients are still blind, it is possible that they function better now than they did before cataract surgery; we do not have the data to assess this.

Although some progress has been made in introducing detection and treatment of leprosy related lagophthalmos, only $56 \%$ of the leprosy control programme sponsored by ILEP programmes report that they measure visual acuity in their patients. ${ }^{23}$ We recommend the following for leprosy control and blindness prevention programmes. Firstly, services must be set up to provide cataract surgery for patients. Some leprosy programmes are fortunate enough to have ophthalmologists associated with them, but most are not. Leprosy control and prevention of blindness programmes will have to make the effort to establish collaborative agreements with whatever ophthalmology services are available for the general public. All possible efforts should be made to ensure that high quality (preferably with IOL implantation) surgery is available, providing upgrade training when necessary to the ophthalmologists. Secondly, patients in need of cataract surgery must be identified and referred. Health workers need to be trained in assessing visual acuity. Surgery probably should be provided earlier to ensure that these patients do not lose their earning capacity. Thirdly, uptake of services should be monitored and investigation made into the barriers that prevent patients from receiving surgery. Fourthly, outcomes of cataract surgery should be monitored to determine whether patients are benefiting from cataract surgery. Monitoring the outcome would also facilitate identification of patients who could benefit from additional spectacle correction to improve visual acuity. Modification to the programme (including referral criteria) could then be made based on evidence from the monitoring programme. There is some effort needed to set up such monitoring systems; however, both leprosy control and blindness prevention programmes are frequently suited for this sort of community based monitoring. The information available from such monitoring is more likely to lead to improved outcomes and better patient satisfaction than blanket recommendations to do specific surgical procedures at specific visual acuities.

As life expectancy increases, cataract will increase as a cause of vision loss and blindness. Leprosy control and blindness prevention programmes will need to ensure that adequate infrastructures are in place to meet these growing needs.

This study was supported in part by LEPRA (British Leprosy Relief Association) to whom we are grateful for support. We have had invaluable support from Mrs Pak Ok-Hyeon and the
staff at the Catholic Skin Clinic and Hospital. We are grateful to the residents of these villages for their cooperation.

1 Courtright P, Lewallen S. Ocular manifestations of leprosy. In: Johnson GJ, Minassian DC, Weale R, eds. The epidemiology of eye disease. London: Chapman and Hall Medical, 1998.

2 Job CK, Thompson K. Histopathological features of lepromatous iridocyclitis: a case report. Int $\mathcal{F}$ Leprosy 1998;66: 29-33.

3 Brandt F, Kampik A, Malla OK, et al. Blindness from cataract formation in leprosy. Dev Ophthalmol 1983;7:1-12. 
4 Waddell KM, Saunderson PR. Is leprosy blindness avoidable? The effect of disease type, duration, and treatment on eye damage from

5 World Health Organization. Progress toward the elimination of leprosy as a public health problem. WHO Wkly Epidemiol $\operatorname{Rec} 1995 ; 26: 177-82$.

6 Waddell K. Intraocular lens implantation for cataract following leprosy. Leprosy Rev 1999; 70:74-5.

7 Batistella GG, Maakaroun M, de Castro AV. Extracapsular cataract extraction and intraocular lens implantation in leprosy patient: visual outcome and complications. Indian $\mathcal{F}$ Leprosy 1998;70:5-10

8 Joko S. Phacoemulsification-aspiration technique with intraocular lens implantation in leprosy patients. Nihon Hansenbyo Gakkai Zasshi 1996;65:170-3.

9 Frucht-Perry J, Feldman ST. Cataract surgery in a leprosy population in Liberia. Int $\mathcal{f}$ Leprosy Other Mycobact Dis population in

10 Lal B, Ghosh A, Singh R, et al. Cataract surgery in patients with leprosy. Philippine f Ophthalmol 1990;19:23-5.

11 ffytche TJ. Cataract surgery in the management of the late ffytche TJ. Cataract surgery in the management of the late
complications of lepromatous leprosy in South Korea. $\mathrm{Br} F$ Ophthalmol 1981;65:243-48.

12 Suryawanshi N, Richaard J. Cataract surgery on leprosy patients. Int $\mathcal{F}$ Leprosy Other Mycobact Dis 1988;56:238-42.

3 Yao J, Qian J. Surgical treatment of secondary cataract in leprosy. Indian f Leprosy 1998;70:145-8.

14 Rao VA, Kawatra VK. Cataract extraction in leprosy patients. Leprosy Rev 1988;59:67-70.
15 Fletcher AE, Donoghue M, Devavaram J, et al. Low uptake of eye services in rural India: a challenge for programs of blindness prevention. Arch Ophthalmol 1999;117:1393-9.

16 Courtright P, Kanjaloti S, Lewallen S. Barriers to acceptance of cataract surgery among patients presenting to district hospitals in rural Malawi. Trop Geogr Med 1995;47: $15-18$.

17 Angra SK, Murthy, GVS, Angra G, et al. Cataract related blindness in India and its social implications. Indian $7 \mathrm{Med}$ Res 1997; 106:312-24.

18 Johnson JG, Goode V, Faal H. Barriers to the uptake of cataract surgery. Trop Doctor 1998;28:218-20.

19 Lewallen S, Tungpakorn NC, Kim SH, et al. Progression of eye disease in "cured" leprosy patients: implications for understanding the pathophysiology of ocular disease and for addressing eye care needs. Br f Ophthalmol 2000;84: 817-21.

20 Courtright P, Lee HS, Lewallen S. Training for primary eye care in leprosy. Bull World Health Organ 1990;68:347-51.

21 Limburg H, Kumar R, Bachani D. Monitoring and evaluating cataract intervention in India. $\mathrm{Br} f$ Ophthalmol 1996;80:951-5

22 Vaidyanathan $\mathrm{K}$, Limburg H, Foster A, et al. Changing trends in barriers to cataract surgery in India. Bull World Health Organ 1999;77:104-9.

23 ILEP Medical Commission. ILEP Medical Commission Survey: prevention of disability in projects sponsored by ILEP members. London: ILEP, 1996.

\section{Contributors please note:}

Communications from all countries except the UK and Republic of Ireland should be sent to Professor C Hoyt, Editor, British fournal of Ophthalmology, University of California, Department of Ophthalmology, 10 Kirkham Street, K 301, San Francisco, CA 94143-0730, USA (tel: 001415 502-6871; fax: 001415 514-1521).

Manuscripts from the UK and the Republic of Ireland should be sent to Professor Andrew Dick, UK Editor, British Fournal of Ophthalmology, Division of Ophthalmology, University of Bristol, Lower Maudlin Street, Bristol BS1 2LX (tel: +44 (0) 0117 929-4496; fax: +44 (0) 117 929-4607). 